\title{
MOVIMENTOS RELIGIOSOS TRANSNACIONAIS: DE REDES A TERRITÓRIOS
}

Kim Knibbe

Resumo: Este artigo, baseado em trabalho de campo multi-situado, descreve igrejas pentecostais transnacionais originárias da Nigéria. A religião é frequentemente descrita como desterritorializada, devido aos processos de globalização. Neste artigo, a autora argumenta que territórios, localidades e lugares são em realidade muito importantes para o pentecostalismo nigeriano transnacional, e que igrejas pentecostais africanas, em geral, constituem territórios e lugares de novas maneiras, assim como acrescentam novas dinâmicas às cidades. $O$ poder persuasivo de criar geografias tangíveis ancoradas em prédios reais, porçóes de terra e instituiçóes é importante para entender como o pentecostalismo transnacional está impactando as esferas públicas ao redor do mundo.

Palavras-chave: Redes religiosas transnacionais, pentecostalismo nigeriano, lógica territorial

Abstract: This article describes transnational Nigerian-initiated Pentecostal churches based on multisited fieldwork. Religion is often described as deterritorialized, due to processes of globalization. In this article, the author argues that territories, localities and places are in fact very important to transnational Nigerian Pentecostalism, and that African Pentecostal churches in general constitute territories and places in new ways as well as add new dynamics to cities. The persuasive power of creating tangible geographies anchored in actual buildings, tracts of land and institutions is important to understand how transnational Penetcostalism is impacting public spheres around the world.

Keywords: Transnational religious networks, Nigerian Pentecostalism, territorial logic

\section{INTRODUÇÃO}

O panorama religioso nigeriano é um dos mais dinâmicos do mundo. Há uma feroz competição entre o islamismo e o cristianismo pela dominância do espaço público. Dentro das igrejas, na rua, no mercado e na mídia há também um vigoroso discurso sobre bruxaria, a magia do dinheiro e o

${ }^{1}$ Pós-Doutroranda da Universidade Livre (Vrije Universiteit) de Amsterdã (Holanda).

Debates do NER, Porto Alegre, Ano io, N. I6, P. 35-47, JUl./Dez. 2009 
sacrifício de vida humana que supostamente a acompanha. O poder sobrenatural é pensando como subjacente ao poder mundano, e portanto disputas de poder são pensadas tanto no mundo sobrenatural como no mundo real (Ellis \& Haar, 2004). Essa disputa, do ponto de vista do cristianismo pentecostal, acontece principalmente através da prece, entrega e conversão.

Muitos pesquisadores têm mostrado com grande detalhe e através de uma análise penetrante o quanto o pentecostalismo é focado na experiência e no corpo, e no papel da mídia neste (p.ex. Meyer e Moors, 2006; Witte, 2008). Como contraste, gostaria de explorar o papel do espaço, lugar e territórios. Este ângulo chamou minha atenção de forma bastante natural ao longo do estudo da expansão do pentecostalismo nigeriano na Europa. Algo central para este projeto de pesquisa era a constatação de que as igrejas pentecostais africanas estão proliferando na Europa, e a pentecostal nigeriana parece liderar a tendência. $\mathrm{O}$ mais famoso exemplo é, certamente, a Igreja Sunday Adelaje em Kiev: um pastor nigeriano liderando uma igreja freqüentada quase que exclusivamente por brancos (Wanner, 2003; Wanner, 2004; Asamoah-Gyadu, 2005).

Essa proliferação tem capturado a atenção de acadêmicos, e formado o pano de fundo do projeto internacional de pesquisa no qual estou atualmente engajada ${ }^{2}$. Neste projeto, três pesquisadores de diferentes universidades trabalham juntos para criar um insight na história e dinâmicas das redes transnacionais pentecostais iniciadas na Nigéria: Dr. Richard Burgess na Universidade de Birmingham, Anna Quaas na Universidade de Heidelberg, e eu, na Universidade Livre de Amsterdã. No transcorrer desta pesquisa temos realizado trabalho de campo multi-situado na Nigéria, na Alemanha, na Holanda e no Reino Unido, tanto em conjunto como separadamente.

\section{REDES RELIGIOSAS TRANSNACIONAIS NIGERIANAS}

O exemplo da Sunday Adelaje esconde a realidade da maioria das igrejas pentecostais originárias da Nigéria na Europa, as quais são frequen-

${ }^{2}$ Ver www.glopent.net.

Debates do NER, Porto Alegre, Ano io, N. I6, P. 35-47, JUl./Dez. 2009 
tadas principalmente por nigerianos e pessoas de outros países africanos. A expansão das igrejas nigerianas segue a diáspora nigeriana e africana, mas não parece ir muito além desta. Neste sentido, parece se encaixar com as observaçóes gerais feitas por Hervieu-Léger, de que uma organização religiosa é caracterizada por redes, ao invés da delineação e dominação de territórios (Hervieu-Léger, 2002). A história da transnacionalização das redes religiosas nigerianas, de acordo com a abordagem "tradicional", é a seguinte: a imigração espalha os nigerianos pelo planeta. Quando há um número suficiente concentrado em uma área, eles iniciarão um grupo de oração, pois sentem falta das igrejas vigorosas a que estão acostumados em casa, e não se sentem confortáveis nas igrejas de seus países anfitrióes por várias razóes (por ter de confrontar racismo implícito ou explicito, ou talvez não ter documentação, ou simplesmente por não gostar da forma e do conteúdo do culto religioso). Este grupo de oração pode, por sua vez, se transformar em uma igreja, fornecendo abrigo, empoderamento e sustento religioso aos imigrantes.

Todo um corpo de literatura surgiu sobre o fenômeno das então chamadas "igrejas imigrantes". Elas são vistas em termos de sua auto-organização e do empoderamento de pessoas relativamente sem poder, conectadas pelos fluxos da imigração transnacional. A meu ver, esta narrativa de transnacionalização da religião é muito limitada e obscurece uma análise das dinâmicas que são geradas por este fenômeno. Isso é o que tentarei mostrar no resto do artigo.

Para começar, muitas "igrejas imigrantes", não são a iniciativa de imigrantes que se sentem alienados da sua sociedade anfitriā, mas o resultado de uma política consciente da parte das "mega-igrejas" pentecostais. As igrejas pentecostais nigerianas tem um discurso missionário muito forte, e políticas estratégias que se combinam a este. Nestes discursos, a noção de territórios a serem conquistados para Jesus tem um papel importante. Seria portanto uma severa limitação enxergar as igrejas que são configuradas fora das fronteiras da Nigéria como a auto-organização de imigrantes relativamente desempoderados e oprimidos. Para mostrar o porquê, deixe-me levar o leitor em um rápido tour por algumas destas igrejas, viajando desde

Debates do NER, Porto Alegre, ANo io, N. I6, P. 35-47, JUl./Dez. 2009 
a Nigéria, seu centro, passando por um poderoso "sub-centro" em Londres, até a periferia em Amsterdã.

\section{VIA EXPRESSA LAGOS-IBADAN, VERÃO DE 2007 :}

Estamos dirigindo pela via expressa entre Lagos e Ibadan, na Nigéria. A estrada é péssima. Uma saída leva para a "Cidade da Oração" de uma igreja chamada Mountain of Fire and Miracles. A saída foi feita pela própria igreja, e é bem pavimentada. A faixa foi nomeada em homenagem ao profeta que levou ao revival nos anos 20 na Nigéria que deu origem a muitas assim chamadas igrejas "Aladura": Avenida Babalola. Descendo esta avenida, entramos uma ampla área onde uma construção está em progresso. Um imenso auditório está sendo construído. Uma série de ruas foi planejada e nomeada. O topo do telhado brilhante de um banco já se ergue em meio à lama. Vemos sinais apontando para prédios designados como escolas, faculdades, e uma universidade. Fica claro que dentro de alguns anos isso será verdadeiramente uma pequena cidade.

Mais além na rodovia, no entanto, entramos um acampamento de oração que já é, em verdade, uma cidade. Este é o Acampamento da Redenção, o centro espiritual do imenso império religioso da Redeemed Christian Church of God. Há um imenso auditório que poderia abrigar centenas de milhares (leva-se um longo tempo para se caminhar da lateral do auditório até o seu centro). Este auditório, no entanto, está sendo substituído por outro que pode abrigar milhóes. Há uma universidade em funcionamento com uma biblioteca excelente que possui computadores com acesso online a periódicos científicos. Há bancos e uma agência postal, várias escolas para os filhos dos pastores, dos trabalhadores da igreja e dos missionários que possuem uma casa no acampamento da redenção. Há ônibus, regulares e escolares. $\mathrm{O}$ centro de conferência onde ficamos hospedados tem uma sala de ginástica. Formando um contraste com as vizinhas Lagos e Ibadan, logo perto, as estradas e casas são bem-cuidadas, o fornecimento de água e eletricidade funciona, e todos os cômodos tem ar-condicionado. Parece

Debates do NER, Porto Alegre, ANo io, N. I6, P. 35-47, JUl./Dez. 2009 
um oásis de "desenvolvimento" no meio de um país marcado pelo colapso, por veículos enferrujados e ruínas.

Mas isso não é tudo que há para ser visto ao longo da via expressa Lagos-Ibadan. De novo, pouco mais adiante, à esquerda de quem vem de Lagos, há outro "acampamento", desta vez de uma organizaçáo muçulmana chamada NASFAT ${ }^{3}$, uma organização de Muçulmanos Yorubá que parece copiar algumas das estratégias bem-sucedidas das mega-igrejas pentecostais, em forma, se não em conteúdo. Uma destas estratégias é o estabelecimento de um "acampamento". Quando passamos por lá, o terreno ainda não havia sido construído, mas uma parede de concreto já o cercava, com o logotipo da NASFAT (Nasrul-Lahi-il Fathi) mostrado proeminentemente por cerca de um quilômetro da rodovia. Atualmente, a organização está buscando recursos para desenvolver o terreno e construir lá sua mesquita nacional ${ }^{4}$.

\section{AMSTERDÃ, INVERNO DE 2009 :}

É domingo, e estamos procurando um prédio em uma área de Amsterdã que é conhecida por sua concentração de africanos e surinamenses, mas também dominada por escritórios, o sudeste de Amsterdã. Uma igreja Christ Embassy é supostamente localizada em um destes prédios de escritórios, o que não é atípico para as igrejas pentecostais na Holanda. Quando encontramos o prédio, eis que a igreja que estamos procurando é apenas uma de várias: os sons altos de oração e devoção de várias igrejas saíam pelas janelas de cada andar, e o prédio está cheio de gente. Quando entramos na sala certa, somos identificados como recém-chegados, ganhamos formulários para preencher e nos é perguntado se gostaríamos de tradução. Há vários tradutores trabalhando em uma cabine, traduzindo as palavras do pastor para microfones conectados a fones de ouvido que são dados a quem os pede. Há tradução para o holandês, polonês, francês, espanhol e alemão. $\mathrm{Na}$ frente do palco, há várias câmeras apontadas para a congregação, que

\footnotetext{
${ }^{3} \mathrm{Ver}<\mathrm{http}: / /$ www.nasfat.org/about.php $>$

${ }^{4}$ Ver <http://thepmnews.com/2009/07/30/nasfat-shops-for-n5b-for-mosque>.
} 
se compõe de mais de cem pessoas. Durante o culto, imagens do "público" são projetadas na parede atrás do palco, nos mostrando para nós mesmo, seja cantando ou rezando ou tomando notas. São-nos dados livrinhos do culto do dia em nossa própria língua (intitulado 'Rapsódia das Realidades', cada livrinho cobre cerca de um mês).

O pastor havia recém retornado de um período de viagem pela Nigéria e outros lugares. Domingo é um dia bastante agitado para ele: são três cultos por dia. Mais tarde, sua esposa nos diz que ambos vieram da Nigéria para montar essa igreja em Amsterdã; existem três outras igrejas Christ Embassy na Holanda.

\section{LONDRES, PRIMAVERA DE 2009:}

Somos levados à sede da Redeemed Christian Church of God em Londres. $\mathrm{O}$ prédio é imenso e branco, em um terreno próprio. O estacionamento é cheio de carros brilhantes. O motorista entra conosco; ele quer uma torta de carne. Quando entramos, eis que todas as tortas de carne já haviam sido vendidas, embora a fila no balcáo do restaurante fosse ainda bastante longa. Somos levados para dentro por assistentes que sabem da nossa presença, pois requisitamos uma entrevista com os líderes dessa igreja. O culto hoje não é realmente um culto: em realidade é a apresentação do relatório anual. Um PowerPoint com fotos de vários projetos e tabelas de recebimentos através de doaçóes e despesas com salários e projetos é mostrado. Mais tarde o pastor reclama que acha bastante cansativo apresentar esse relatório anual ao invés de liderar um culto "real" quando a presença do Espírito Santo é mais tangível. Mas é necessário: devem-se prestar contas.

Embora isso não seja dito explicitamente, há uma clara consciência dos escândalos envolvendo igrejas nigerianas e suas práticas contábeis na Inglaterra, e assim a RCCG tem algo a provar. Antes de sair, ganhamos um CD com a apresentação do dia gravado. No hall de entrada, olhamos a maquete da nova sede planejada. Será como um centro de conferências, com todas as instalaçóes necessárias para encontros, estudos, hospedagem,

Debates do NER, Porto Alegre, ANo io, N. I6, P. 35-47, JUl./Dez. 2009 
alimentação, esportes, e é claro, oração e devoção, localizada em um imenso terreno já comprado. Ao lado do modelo do centro de conferência, fica um caixa eletrônico.

\section{DE VOLTA A AMSTERDÁ :}

Algumas semanas depois, vários dos pastores com os quais conversamos em Londres estão em uma conferência na filial de Amsterdã da RCCG. A conferência é intitulada "O Coração e Alma da Igreja”, e destina-se a pastores e trabalhadores da igreja que tem se esforçado para iniciar novas igrejas. Presentes na conferência estão pastores da RCCG que lideram paróquias de toda a Europa, assim como vários pastores de igrejas pentecostais africanas em Amsterdã, e o presidente do Conselho de Igrejas Pentecostais de Amsterdã. A delegação de Londres apresenta a história de sucesso na cidade a estes missionários: como criar crescimento, como gerenciar o crescimento, a importância de práticas contábeis boas e transparentes, estruturas administrativas claras, e linhas de comunicação abertas.

Acima de tudo, eles enfatizam que, para ser um missionário bem sucedido, deve-se ter uma "obrigação para com o lugar". Do ponto de vista da RCCG, o lugar pode parecer algo arbitrário, simplesmente um ponto no mapa-múndi onde há trabalho, ou onde Deus chamou um missionário para plantar uma igreja. No entanto, isso não é suficiente: um missionário deve entender as necessidades e problemas de um lugar, para ser bem-sucedido. Deve usar as peculiaridades de um lugar para alcançar as pessoas. Em Londres, eles dão o exemplo da lavagem de carro grátis: enquanto as pessoas estão ganhando uma lavagem de carro grátis, elas estão engajadas em uma conversa sobre Cristo. Na Holanda, o jovem pastor de Londres sugere, isso pode ser feito através de oferta de reparos de bicicleta gratuitos.

Os missionários que lideram paróquias menores e mais jovens escutam atentamente, se aquecendo no fogo do sucesso de Londres, e mantendo vivos seus sonhos de um dia liderar congregações tão grandes quanto esta. A filial de Amsterdã tem claramente se planejado para um crescimento

Debates do NER, Porto Alegre, ano io, N. I6, P. 35-47, JUl./Dez. 2009 
espetacular: compraram um grande prédio, com o valor de entrada pago pela sede nigeriana e pela paróquia londrina. No presente, estão lutando para pagar a hipoteca, e alugam espaço no prédio para várias outras igrejas pentecostais africanas.

\section{CRIANDO GEOGRAFIAS TANGÍVEIS}

O 'tour' feito acima nos levou a vários lugares e igrejas. Das igrejas mencionadas nestas descrições, a Redeemed Christian Church of God é a maior e mais antiga. Essa igreja emergiu do movimento Aladura após a Segunda Guerra Mundial ${ }^{5}$. Até o início dos anos 90, ela permaneceu relativamente pequena, sob a liderança de seu fundador, Josiah Akindayomi. No entanto, sob a liderança de seu sucessor, Enoch Adejare Adeboye, a igreja começou a crescer fenomenalmente (Ukah, 2008). Este crescimento continua até os dias de hoje. Eles estão presentes na maioria dos países do mundo, e querem estar presentes em cada nação do mundo antes do final do ano 2010. A RCCG desenvolveu uma política de fundação de sedes extremamente pró-ativa que é aparentemente muito bem-sucedida. Esta política é incorporada em uma declaração de missão muito precisa que pode ser encontrada em muitos sites da RCCG, e que é frequentemente mencionada em conversas:

1. Criar o paraíso.

2. Levar conosco o maior número de pessoas possível.

3. Ter um membro da RCCG em cada família de todas as naçóes.

4. Para conquistar o número 1 acima, a santidade será nosso estilo de vida.

${ }^{5} \mathrm{O}$ movimento Aladura foi um movimento de revival cristão na Nigéria com uma grande ênfase na cura e milagres. De acordo com alguns estudiosos do pentecostalismo, deve ser visto como um movimento pentecostal africano. Na Nigéria atual, no entanto, a maioria das igrejas pentecostais não quer mais ser associada com as igrejas Aladura (ou espirituais), colocando ênfase em um estilo de vida de "santidade" e ao mesmo tempo, no caso das igrejas descritas acima, pregando um evangelho da prosperidade.

Debates do NER, Porto Alegre, ANo io, N. I6, P. 35-47, JUl./Dez. 2009 
5. Para conquistar os números 2 e 3 acima, plantaremos igrejas a cada cinco minutos de caminhada em cada cidade de países em desenvolvimento, e a cada cinco minutos de carro em cada cidade de países desenvolvidos.

6. Seguiremos estes objetivos até que cada Nação do Mundo seja alcançada pelo Nosso Senhor Jesus Cristo.

De acordo com seu próprio estatuto de missão, a RCCG deve produzir localidades, mais precisamente igrejas, para ser bem-sucedida (Knibbe, 2009). Toda a organização da igreja é voltada para isso. A RCCG tem um programa de treinamento bastante ativo para que empregados da igreja se tornem diáconos e depois pastores, os preparando para fundarem uma nova igreja. Na Nigéria, existem áreas onde o objetivo de ter uma igreja a cada cinco minutos de caminhada já foi atingido. Em outras áreas da Nigéria e ao redor do mundo, este nível de saturação ainda está bem distante. Mesmo assim, na Europa a RCCG tem centenas de paróquias no Reino Unido, cerca de 20 na Holanda e cerca de sete na Alemanha. Em outros países europeus, a RCCG está crescendo, especialmente no sul da Europa e na Europa oriental. Em comparação, a Mountain of Fire and Miracles tem 72 igrejas no Reino Unido, nove na Holanda e duas na Alemanha ${ }^{6}$. A Christ Embassy, em contraste, parece contar seu sucesso não em termos do número de filiais mas em termos do número de línguas em que seu material de ensino principal (os livrinhos da Rapsódia das Realidades) estão traduzidos (no momento, 84). Há quatro filiais na Holanda, das quais descrevi a sede em Amsterdã.

Cada uma dessas igrejas tem estratégias organizacionais levemente

\footnotetext{
${ }^{6}$ Para o Reino Unido, ver <http://www.mountainoffire.co.uk/branches.htm $>$. Para a Holan$\mathrm{da}$, ver <http://www.mountainoffire.co.uk/branches.htm >. Para a Alemanha, ver <http:// www.mountainoffire.org/network.html >. Estes números não são muito "sólidos" já que as igrejas vêm e vão dependendo da presença de um pastor e de um local de devoçáo. A MFM se baseia menos em nigerianos 'expatriados', mas envia pastores da Nigéria com um visto temporário para manter a presença na Europa (com exceção do Reino Unido, que tem uma grande população nigeriana).
}

Debates do NER, Porto Alegre, Ano io, N. 16, P. 35-47, JUl./DeZ. 2009 
diferentes. É importante perceber que há outro ângulo possível, o qual não elaborei aqui, e que parte de uma localidade em particular. Um exemplo é o sudeste de Amsterdã, onde muitas igrejas pentecostais africanas estão localizadas. Em um intervalo de cerca de 20 anos, mais de uma centena de igrejas brotaram nessa vizinhança, a qual foi originalmente planejada para uma era secular. A vizinhança tem uma fama péssima: pobre, negra e com um alto índice de criminalidade. As igrejas frequentemente se utilizam de prédios de estacionamento vazios, construídos para as classes médias que deveriam supostamente viver ali. Em anos recentes, a administração municipal tentou instigar um processo de renovação, derrubando os velhos prédios altos e investindo novamente em habitação para a classe média. Este processo de renovação tornou o espaço ainda mais escasso, aumentando a competição entre as igrejas por espaço (Meulen, 2009). Nesta competição local por espaço, as igrejas que são parte de instituições transnacionais como a RCCG levam uma boa vantagem.

Apesar das diferenças entre as diferentes igrejas apresentadas nas descrições acima, podemos elaborar várias conclusões. A primeira é a de que as igrejas pentecostais nigerianas na Europa se concebem como igrejas missionárias e tem grandes planos. Planos enormes, na verdade. O tamanho é importante. Ao longo da via-expressa Lagos-Ibadan, a competição entre os movimentos religiosos é clara, assim como o movimento que está ditando as tendências: a Redeemed Christian Church of God. Central aos "grandes planos" destas igrejas é a aquisição de prédios e terrenos para criar uma geografia mundial tangível. Embora a Christ Embassy não pareça se importar tanto com terra e prédios como as outros duas, colocando seu foco na mídia, a sua filial de Amsterdã estava muito entusiasmada pela compra de seu próprio prédio quando os visitamos. Para qualquer igreja missionária, a aquisição de um lugar de devoção é uma questão central, mas o valor anexado à aquisição de solidez através de prédios é maior do que este simples requerimento prático.

Em um artigo previamente publicado, usei esta frase de um pastor de Amsterdã como título: "não viemos aqui como inquilinos, mas como senhorios!” (Knibbe, 2009). Ele fez essa afirmação para se contrapor à noção

Debates do NER, Porto Alegre, Ano io, N. I6, P. 35-47, JUl./Dez. 2009 
prevalecente em alguns círculos na Holanda de que os imigrantes (especialmente os africanos) vêm para a Holanda para ter uma vida melhor, que são pobres e passam dificuldades, e que as igrejas dos imigrantes devem ganhar "ajuda" para adquirir um local de devoção. Ele veio plantar uma igreja, e na realidade desistiu de uma carreira bancária bem-sucedida na Nigéria. Os líderes da RCCG na Holanda se colocam auto-conscientemente como 'expatriados' ao invés de imigrantes. Outras filiais na Holanda já adquiriram um prédio, ou estão no processo de aquisição. Velhas igrejas católicas ou protestantes são às vezes adquiridas.

Para adquirir prédios e terra, redes são importantes. As redes que governam a expansão deste império religioso são verdadeiramente transnacionais: os pastores frequentemente viajam entre Londres, Estados Unidos, Nigéria e outros países africanos e a Europa continental. O crescimento usualmente se dá de acordo com a lógica de rede. Por exemplo, alguém que frequenta a paróquia da RCCG na Holanda e trabalha para a Shell é transferido para os Estados Unidos. Se esta pessoa passou por algum treinamento como empregado da igreja, ele será encorajado para usar essa oportunidade e iniciar uma nova igreja; plantar uma "paróquia-filha". Em outros casos, programas religiosos de oração e jejum resultam em um ou mais "chamados" ('daughter parish'7), como no caso do pastor da paróquia de Amsterdā. Se há muitas paróquias plantadas com origem em uma 'paróquia-mãe', todas estas paróquias formam uma rede de pessoas que começaram suas 'carreiras espirituais' sob a liderança de um pastor, talvez particularmente carismático. Existem muitas destas redes, e recentemente Adeboye tem se manifestado contra elas, expressando o medo de que estas redes se transformem no "reino" do pastor líder.

Isso tem impulsionado uma ênfase renovada no Reino Unido e na Europa na estrutura administrativa baseada em unidades territoriais. $\mathrm{Na}$ Holanda, uma nova paróquia é de início apoiada pela sede nacional, e pela paróquia da qual os missionários são enviados. Em alguns casos, é por

${ }^{7} \mathrm{O}$ termo "paróquia", normalmente associado a organização eclesiástica católica, é utilizado pelo grupo pentecostal em questão (Nota dos editores).

Debates do NER, Porto Alegre, Ano io, N. I6, P. 35-47, JUl./Dez. 2009 
outra paróquia holandesa, mas no caso de Amsterdã, por exemplo, era por uma paróquia de Lagos. Depois de um tempo, espera-se a paróquia comece a enviar dinheiro para a sede da área, a qual deve enviar para a sede da província, da zona, e a sede nacional. Essa obrigação de remeter dinheiro ás vezes leva a críticas internas: pastores são dependentes da sua paróquia para seus rendimentos, e consequentemente tem um grande incentivo para pressionar os paroquianos a doar dinheiro.

\section{CONCLUSŌES}

Embora o pentecostalismo transnacional nigeriano cresça de acordo com uma lógica de rede, alguns dos movimentos, especialmente os maiores, tem desenvolvido estruturas administrativas e políticas missionárias que possuem uma lógica territorial e se apóiam fortemente no poder persuasivo de estruturas tangíveis, prédios e seu tamanho. Além disso, a expansão das igrejas pentecostais pode criar novas dinâmicas em cidades ao redor do globo. Em Londres e Amsterdã, a competiçáo por espaço, tamanho e devotos transforma os panoramas urbanos e afeta as políticas das administraçóes locais. Em Amsterdã, isso levou a um panorama religioso local que está definindo, em grande medida, uma vizinhança específica do sudeste de Amsterdã. Para caracterizar as religiōes atuais como "redes" ou a auto-organização de imigrantes marginalizados encontrando apoio e empoderamento na religião é portanto deixar de lado algumas das mais importantes consequências que o crescimento destas igrejas tem na esfera pública européia.

\section{REFERÊNCIAS BIBLIOGRÁFICAS}

ASAMOAH-GYADU, J. K. An African Pentecostal on Mission in Eastern Europe: The Church of the "Embassy of God" in the Ukraine. PNEUMA: The Journal of the Society for Pentecostal Studies. Cleveland (USA), vol. 27, n. 2, 2005.

ELLIS, S. \& HAAR, G. T. Worlds of Power. Religious Thought and Political Practice in Africa. London: Hurst and Company, 2004.

Debates do NER, Porto Alegre, Ano io, N. I6, P. 35-47, JUl./Dez. 2009 
HERVIEU-LÉGER, D. Space and Religion: New Approaches to Religious Spatiality in Modernity. International Journal of Urban and Regional Research. Vol. 26, n. 1, 2002, p. 99-105.

KNIBBE, K. (2009). "We did not come here as tenants, but as landlords". Nigerian pentecostals and the power of maps. African Diáspora. Vol 2, n. 2, 2009, p. 133158.

MEULEN, M. v. d. The Continuing Importance of the Local. African Churches and the Search for Worship Space in Amsterdam. African Diaspora. Vol. 2, n. 2, 2009, p. 159-181.

MEYER, B. \& MOORS, A. (orgs). Religion, Media and the Public Sphere. Bloomington and Indianapolis: Indiana University Press, 2006.

UKAH, A. A New Paradigm of Pentecostal Power. A study of the Redeemed Christian Church of God in Nigeria. Trenton NJ and Asmara: Africa World Press, 2008.

WANNER, C. Advocating New Moralities: Conversion to Evangelicalism in Ukraine. Religion, State and Society. Vol. 31, n. 3, 2003, p. 273-287.

WANNER, C. Missionaries of Faith and Culture: Evangelical Encounters in Ukraine. Slavic Review. Vol, 63, n. 4, 2004, p. 732-755.

WITTE, M. d. Spirit Media. Charismatics, traditionalists, and mediation practices in Ghana. Tese (Doutorado)-Amsterdam School for Social Science Research, Amsterdam, University of Amsterdam, 2008.

Traduzido por Nicole Reis. 
